\title{
Two cases of left superior vena cava draining directly to a left atrium with a normal coronary sinus
}

Henry B Wiles

\begin{abstract}
The most common variation in the thoracic systemic venous system is a persistent left superior vena cava draining to a coronary sinus. A rare anomaly is a persistent left superior vena cava connecting directly to the left atrium. In this situation it is believed that the coronary sinus must be absent. This report describes two cases of a persistent left superior vena cava draining to a left atrium with a normal coronary sinus.
\end{abstract}

The embryological development of systemic and pulmonary veins is complex and subject to considerable variation. The early, symmetrical cardinal veins ultimately give rise to the superior systemic venous channels while the splanchnic plexus of the foregut gives rise to the pulmonary venous channels. Most of the left sided cardinal system disappears, leaving only the coronary sinus to drain the cardiac veins and a remnant known as the ligament of Marshall. Many variations and abnormalities of venous development have been described..$^{1-3}$ One variation is the persistence of a left superior vena cava, ${ }^{4}$ which usually drains into the coronary sinus. A rare abnormality is the presence of a persistent left superior vena cava draining directly into the left atrium. ${ }^{56}$ It is often stated that a persistent left superior vena cava draining into the left atrium is associated with an absent coronary sinus. We describe two patients in whom a persistent left superior vena cava draining to the left atrium was associated with a normal coronary sinus.

\section{Case reports}

CASE 1

A two year old child with tetralogy of Fallot had cardiac catheterisation before elective surgical repair. His clinical course was unremarkable except for slowly progressive cyanosis. Haemodynamic evaluation during catheterisation showed an unrestrictive ventricular septal defect (right and left ventricular peak pressures $90 \mathrm{~mm} \mathrm{Hg}$ ), infundibular and pulmonary valve stenosis (main pulmonary artery peak pressure $12 \mathrm{~mm}$ $\mathrm{Hg}$ ), and unobstructed left ventricular outflow (right femoral artery peak pressure $110 \mathrm{~mm}$ $\mathrm{Hg}$ ). Oximetry did not show a left to right shunt (mixed venous $71 \%$ and main pulmonary artery $69 \%$ ). There was right to left shunting at both the atrial and ventricular levels (pulmonary vein $96 \%$, left atrium $93 \%$, left ventricle $93 \%$, and femoral artery $86 \%$ ).

Both catheterisation and angiography showed a persistent left superior vena cava connected to the roof of the left atrium (fig 1). The left superior vena cava ran in front of the left pulmonary artery and was connected to the normal left innominate vein at its junction with the left subclavian vein. There was also a normal right superior vena cava and a patent foramen ovale. The catheter passed anterogradely from the left superior vena cava into the left atrium as well as retrogradely from the left atrium into the left superior vena cava. The catheter also passed from the right atrium into the coronary sinus, which did not communicate with any systemic vein except the cardiac veins (fig 2 ). The pulmonary veins were connected to the left atrium.

\section{CASE 2}

A nine month old infant had a complete atrioventricular canal, pulmonary hypertension, and failed to thrive. He underwent cardiac catheterisation before pulmonary artery banding. At catheterisation the right and left ventricular peak pressures were equal $(70 \mathrm{~mm} \mathrm{Hg})$. Oxygen saturation data measured by oximetry showed a left to right shunt at the atrial and ventricular levels (mixed venous $63 \%$, right atrium $81 \%$, right ventricle $85 \%$, and main pulmonary artery

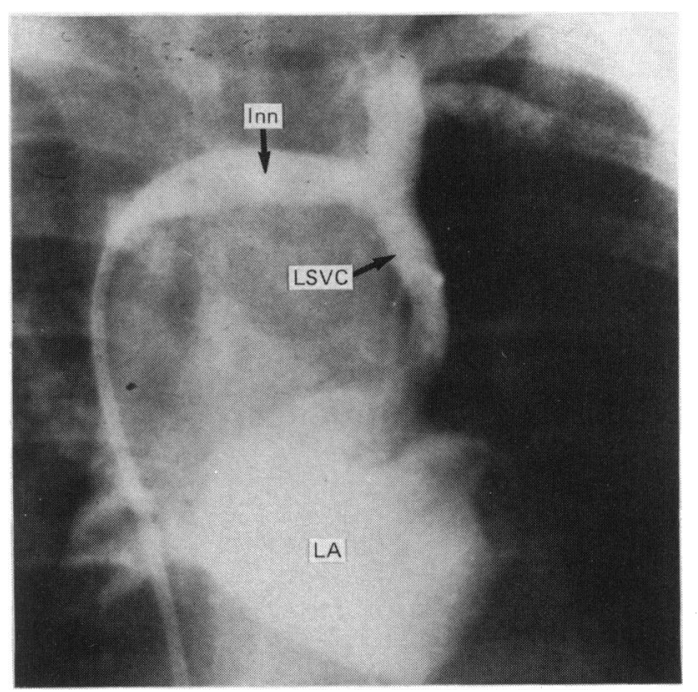

Figure 1 Angiogram showing the connection of the persistent left superior vena cava (LSVC) to the roof of the left atrium $(L A)$. The catheter passed from the right atrium through the right superior vena cava and left innominate vein (Inn) into the left superior vena cava. 


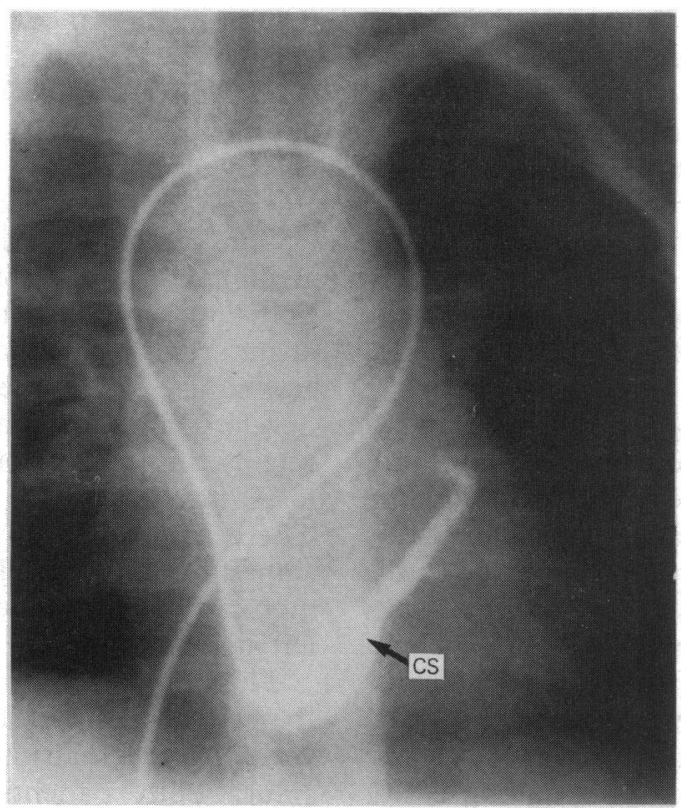

Figure 2 Angiogram showing that the normally formed coronary sinus (CS) is separate from the left superior vena cava (see fig 1). The catheter course is inferior vena cava, right atrium, patent foramen ovale, left atrium, left superior vena cava, innominate vein, right superior vena cava, right atrium, and mouth of the coronary sinus.

$85 \%$ ). Data were not collected to document the degree of right to left shunting.

Angiography and the catheter course showed a persistent left superior vena cava connected to the roof of the left atrium. This vein ran in front of the left pulmonary artery and was connected to the left subclavian vein.
There was no bridging left innominate vein The pulmonary veins entered the left atrium as normal.

The postoperative course was complicated and the patient died 27 days after operation. At necropsy the findings at catheterisation were confirmed: complete atrioventricular canal and a persistent left superior vena cava to the left atrium. In addition, a normal coronary sinus was found with normal connection to the right atrium. This coronary sinus was not connected to any systemic vein other than the cardiac veins.

\section{Discussion}

Embryological development of the systemic veins involves the umbilical, vitelline, and cardinal venous systems. The anterior and posterior cardinal veins join to form the right and left common cardinal veins which empty into the sinus horns and then into the primitive atria. Invagination of the sinus horns, which causes both the common cardinal veins to empty into the right atrium, and obliteration of the anterior cardinal vein leaves the normal coronary sinus, with absence of the left superior vena cava, as found in the mature heart. ${ }^{7}$ Many variations and abnormalities of this development have been reported. The most common thoracic venous abnormality is the persistent left superior vena cava draining into the coronary sinus as reported in $3-10 \%$ of patients with congenital heart disease. ${ }^{89}$ This variation in isolation results in no haemodynamic compromise. A more uncommon
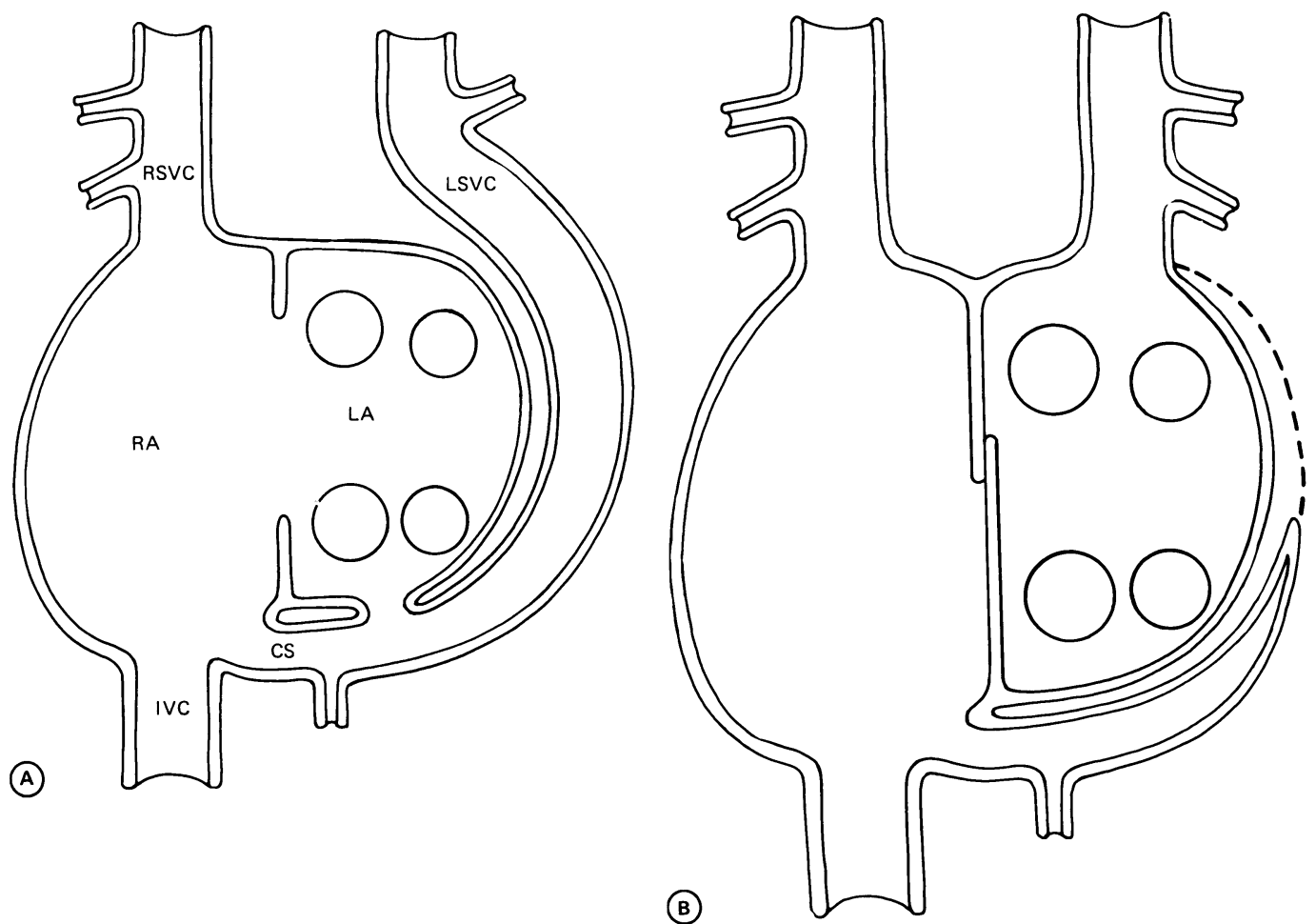

Figure 3 A theory to explain the association between a persistent left superior vena cava (LSVC) to left atrium and a normal coronary sinus. ( $A$ ) The left superior vena cava retains a communication with the left atrium ("unroofed") while the coronary sinus develops normally. (B) If this communication persists and the left superior vena cava does not regress, then both a left superior vena cava to left atrium and coronary sinus can exist together. $L A$, left atrium; regress, then both a left superior vena cava to left atrium and coronary sinus can exist together. $L A$, left atrium;
$R A$, right atrium; $R S V C$, right superior vena cava; $L S V C$, left superior vena cava; IVC, inferior vena cava; $C S$, coronary sinus. (Adapted from Lucas RV. Anomalous venous connections, pulmonary and systemic. In: Adams FH, Emmanouilides GC, eds. Moss' heart disease in infants, children, and adolescents. 3rd ed. Baltimore: Williams and Wilkins, 1983:483.) 
abnormality is the persistence of a left superior vena cava connecting directly to the left atrium. This anomaly was found in about $7 \cdot 5 \%$ of cases of persistent left superior vena cava, ${ }^{10}$ and it results in a small right to left shunt. This lesion has little haemodynamic effect, mainly a variable degree of systemic cyanosis.

Various workers believe that the embryological anomaly of the left superior vena cava connecting into the left atrium cannot exist with a normal coronary sinus. ${ }^{6711}$ Presumably a left superior vena cava is produced when the left common cardinal vein and the left sinus horn are incorporated into the right atrium during invagination of the sinus horns and the left atrium. Failure of this invagination allows the left superior vena cava to remain connected to the left atrium and makes development of the coronary sinus impossible (fig 3). If this were true then an atrial septal defect of the coronary sinus type should be present in every case. This finding is not present in all reported cases.

Edwards and DuShane described one patient who had a connection to the left atrium, pulmonary veins, and systemic veins via a "levoatriocardinal vein". 1 This patient had mitral atresia with a closed foramen ovale. Presumably in this patient this vein carried pulmonary venous blood away from the left atrium. Lucas et al described a similar case of severe left atrial obstruction with a "levoatriocardinal vein" draining pulmonary venous return. ${ }^{12}$ Anomalies of pulmonary venous connections often involve veins connecting the common pulmonary confluence with the left innominate vein. These connecting veins have often been termed "vertical veins" and are not considered to be a truly persistent left superior vena cava. ${ }^{713}$

Mantini et al described anomalies of the coronary sinus, including connection to the left atrium and pulmonary veins.$^{14}$ One patient had atresia of the mouth of the coronary sinus with the distal end of the coronary sinus connected to the left atrium in association with a left superior vena cava that was also connected to the left atrium. When a portion of the atrial wall near the mouth of the coronary sinus is missing (coronary sinus atrial septal defect) or when the coronary sinus is "unroofed" there is usually a communication between the coronary sinus and left atrium.

We report two patients with a truly persistent left superior vena cava connected directly to the left atrium in association with a normally formed coronary sinus. These systemic veins were regarded as true left superior venae cavae because they connected to the roof of the left atrium, did not connect to or drain the pulmonary veins, passed in front of the left pulmonary artery and aortic arch, and connected to the left innominate vein or left subclavian vein in this instance without a left innominate vein. "Vertical veins" and "levoatriocardinal veins" do not have these characteristics. In addition, the coronary sinus was clearly seen by either angiography or direct visualisation. Figure 3 shows a theory to explain this association of left superior vena cava with left atrium and normal coronary sinus. A connection between the left cardinal vein and left atrium remains (similar to an unroofed coronary sinus) while the distal coronary sinus develops normally. The left superior vena cava retains this connection to the left atrium but loses its connection to the coronary sinus. There is no obvious reason for the coronary sinus to become involved when the left common cardinal vein retains a connection with the left atrium.

This report shows the association between the rare anomaly of a persistent left superior vena cava to left atrium and a normal coronary sinus. Both patients described had other cardiac malformations requiring catheterisation which showed the additional venous abnormality. We do not know whether this rare association ever occurs without other intracardiac malformations. The haemodynamic results of a small right to left shunt in such a situation are unlikely to be noticeable.

1 Edwards JE, DuShane JW. Thoracic venous anomalies. Arch Pathol 1950;49:517-37.

2 Edwards JE. Congenital malformations of the heart and great vessels: I. Malformations of the thoracic veins. In: Gould SE, ed. Pathology of the heart and blood vessels. 3rd ed. Springfield, Illinois: Charles C Thomas, 1968:463-78.

3 Park $H$, Summerer MH, Preuss $\mathrm{K}$, Armstrong WF, Mahomed Y, Hamilton DJ. Anomalous drainage of the right superior vena cava into the left atrium. $\mathrm{J} \mathrm{Am}$ Coll Cardiol 1983;2:358-62.

4 Fraser RS, Dvorkin J, Rossall RE, Eidem R. Left superior vena cava: a review of associated congenital heart lesions, catheterization data and roentgenologic findings. $\mathrm{Am} \mathrm{J}$ Med 1961;31:711-6.

5 Schick EC, Likakis J, Rothendler JA, Ryan TJ. Persistent left superior vena cava and right superior vena cava drainage into the left atrium without arterial hypoxemia. $J$ Am Coll Cardiol 1985;5:374-8.

6 Raghib G, Ruttenberg HD, Anderson RC, Amplatz K, Adams $P$, Edwards JE. Termination of left superior vena cava in left atrium, atrial septal defect, and absence of coronary sinus: a developmental complex. Circulation coronary sinus:

7 Lucas RV. Anomalous venous connections, pulmonary and systemic. In: Adams FH, Emmanouilides GC, eds. Moss' heart disease in infants, children, and adolescents. 3rd ed. Baltimore: Williams and Wilkins, 1983:458-91.

8 Anderson RC, Adams P, Burke B. Anomalous inferior vena cava with azygos continuation (infrahepatic interruption of the interior vena cava). $J$ Pediatr 1961;59:370-83.

9 Campbell M, Deuchar DC. The left-sided superior vena cava. Br Heart J 1954;16:423-39.

10 Meadows WR, Sharp JT. Persistent left superior vena cava draining into the left atrium without arterial oxygen unsaturation. Am J Cardiol 1965;16:273-9.

11 Sherman FE. An atlas of congenital heart disease. Philadelphia: Lea and Febiger, 1963:67-8.

12 Lucas RV, Lester RG, Lillehei CW, Edwards JE. Mitral atresia with levoatriocardinal vein: a form of congenital pulmonary venous obstruction. Am J Cardiol 1962;9: 607-13.

13 Gott VL, Lester RG, Lillehei CW, Varco RL. Total anomalous pulmonary return: an analysis of thirty cases. Circulation 1956;13:543-52

14 Mantini E, Grondin CM, Lillehei CW, Edwards JE. Congenital anomalies involving the coronary sinus. Circulation 1966;33:317-27. 